\title{
RETENÇÃO DE ÁGUA EM DOIS TIPOS DE LATOSSOLOS SOB DIFERENTES USOS ${ }^{(1)}$
}

\author{
A. N. BEUTLER ${ }^{(2)}$, J . F. CENTURION ${ }^{(3)}$, Z. M. SOUZA(2), \\ I. ANDRIOLI(3) \& C. G. ROQUE ${ }^{(2)}$
}

\begin{abstract}
RESUMO
A curva de retenção de água é específica a cada solo e depende de vários atributos do solo. Assim, objetivou-se avaliar a influência de atributos do solo na retenção de água em Latossolo Vermelho distrófico (LVd) e Latossolo Vermelho eutrofér rico (LVef) sob diferentes sistemas de uso e manejo. Os sistemas de uso e manejo foram: algodão, cana-de-açúcar e mata. As amostras de solo foram coletadas nas profundidades de 0-10, 10-20, 20-30 e 30-40 cm, para determinar a composição granulométrica, densidade do solo, matéria orgânica, $\mathrm{Fe}_{2} \mathrm{O}_{3}, \mathrm{Al}_{2} \mathrm{O}_{3} \mathrm{e}$ a curva de retenção de água. A matéria orgânica não demonstrou participação efetiva na retenção de água, e a densidade do solo revelou maior correlação positiva com a retenção de água. $0 \mathrm{~L}$ Vef apresentou maior retenção de água em todas as tensões e a mesma capacidade de água disponível (CAD) em relação ao LVd.
\end{abstract}

Termos de indexação: água no solo, matéria orgânica, densidade do solo, óxidos de ferro e alumínio.

\section{SUMMARY: WATER RETENTION IN TWO OXISOLS UNDER DIFFERENT USES}

For every type of soil, the water retention curve is specific and depends on several soil features. This study was carried out to evaluate the influence of soil attributes on water retention in Red Latosol (Haplustox) and Red Latosol (Eutrustox) under different management and use systems. The use systems were: cotton, sugar-cane and woods. The granul ometric composition, bulk density, organic matter, $\mathrm{Fe}_{2} \mathrm{O}_{3}$ and $\mathrm{Al}_{2} \mathrm{O}_{3}$ contents, as well

(1) Recebido para publicação em dezembro de 2001 e aprovado em maio de 2002.

(2) Doutorando do Departamento deSolos eAdubos, Faculdade de Ciências Agrárias e Veterinárias - UNESP. Via de acesso Prof. Paulo Donato Castellane s/n, CEP 14870-000 J aboticabal (SP). Bolsista da FAPESP. E-mail: amaurib@yahoo.com.br

(3) Professor Adjunto do Departamento de Solos e Adubos, UNESP. E-mail: jfcentur@fcav.unesp.br 
as the water retention curve were determined for soil samples from different depths (0-10, 10-20, 20-30 and 30-40 cm). Organic matter did not demonstrate effective participation in water retention, whilethe attribute bulk density had the greatest positive correlation with water retention. Eutrustox soil presented greater water retention in all tensions and, in relation to Haplustox, the same capacity of available water (CAW).

Index terms: soil water, organic matter, bulk density, aluminum and iron oxi des.

\section{INTRODUÇÃO}

O cultivo do solo promove modificações nos atributos físicos, principalmente na estrutura, que podem favorecer o crescimento das culturas, a curto prazo. Entretanto, o cul tivo intensivo, durante vários anos, pode degradar os solos, alterando a retenção de água, reduzindo a produtividade e aumentando os custos de produção. N este contexto, os atributos que influem na retenção de água no solo têm sido intensamente estudados por ser a água um dos fatores limitantes à produtividade das culturas.

O conteúdo deágua reti do no sol o em determi nada tensão é característica específica de cada solo e é resultado da ação conjunta e complexa de vários fatores. Este depende do teor emineralogia da fração argila, do teor de matéria orgânica, das diferenças da mi croestrutura com el as relacionadas (Grohmann \& Medina, 1962; Reichardt, 1987) e da compactação do solo (Silva et al., 1986).

Para al tos conteúdos deágua, nos quais fenômenos capilares são de importância na retenção de água, esta depende da densidade do solo e da porosidade, enquanto, para menores conteúdos de água, em que o fenômeno de adsorção domina, depende mais da textura eda superfície específica do solo (Hillel, 1970; Demattê, 1988).

Grohmann \& Medina (1962), estudando vários solos, verificaram que a retenção de água foi positivamente influenciada pelo teor de argila em sol os cultivados e que, em sol o sob mata, a retenção de água, em diferentes profundidades, mostrou-se dependente do teor de matéria orgânica, quando esta variou de 8 a $68 \mathrm{~g} \mathrm{~kg}^{-1}$, diminuindo, assim, a retenção de água com o aumento da profundidade. Neste sentido, Reichardt (1987) afirma que a textura é o principal determinante da retenção de água, por atuar diretamente na área de contato entre as partículas sólidas e a água.

Maior retenção de água, em todas as tensões, foi verificada em solos de textura mais fina por Kiehl (1979), Silva et al. (1986), Brady (1989), Carvalho et al. (1999) e Dias J unior \& Estanislau (1999); em sistemas com maior teor de matéria orgânica, por Vieira (1981), Sidiras et al. (1984) e Carvalho et al . (1999); em solos sob floresta com maior teor de matéria orgânica, em comparação com solos cultivados, por Silva et al. (1986) e Brady (1989); e em sol os mais compactados, por Sidiras et al . (1983), Centurion \& Demattê (1985); Corsini et al. (1986), Silva et al. (1986), Brady (1989) e Eltz et al. (1989).

Portela et al. (2001) verificaram que o cultivo de citrus aumentou a densi dade do sol o e a retenção de água em relação à mata a qual não diferiu do cultivo com mandioca. No entanto, a área com citrus apresentou menor capacidade deágua disponível na profundidade de $10 \mathrm{~cm}$, não alterando a retenção de água na profundidade de $30 \mathrm{~cm}$, mesmo com maior densidade do solo.

Os Latossol os são de mai or expressão geográfica no território brasileiro; todavia, as diferenças entre L atossol os cauliníticos e oxídi cos quanto à retenção deágua não estão estabel ecidas na literatura. Assim, objetivou-se avaliar a retenção deágua em L atossolo Vermelho distrófico e Latossolo Vermelho eutroférrico sob diferentes sistemas de uso e manejo.

\section{MATERIAL E MÉTODOS}

O estudo foi realizado em um $L$ atossolo Vermel ho distrófico típico textura média/argilosa A moderado caulinítico ( $L V d)$ e em Latossolo Vermelho eutroférrico, típico, textura argilosa/argilosa $A$ moderado caulinítico-oxídico (LVef). Os sol os estão localizados na mesma área experimental, sendo o LVd localizado em maior altitude. As coordenadas geográficas da área experimental são de 21008'27" de latitude sul e 48'16'17" de longitude oeste, localizada no município de J aboticabal (SP). O clima é mesotérmico de inverno seco (Cwa), pelo critério de classificação climática de Köppen. Os atributos físicos e químicos dos solos são apresentados no quadro 1.

Os sistemas de uso emanejo foram: algodão, canade-açúcar (5o ano) e mata nativa. Na área com algodão, foi feito o preparo com arado de discos, grade aradora e quatro gradagens niveladoras, tendo sido essa área cultivada durante 30 anos com culturas anuais. $\mathrm{Na}$ área com cana-de-açúcar, foi realizado preparo convencional, utilizando arado de discos, grade aradora e subsolagem no preparo do solo, sendo feita a quei ma antes do corte enão foi aplicada vinhaça no solo, durante 30 anos. 


\section{Quadro 1. Atributos físicos e químicos do LVd e LVef, nos sistemas de uso e manejo e em diferentes profundidade}

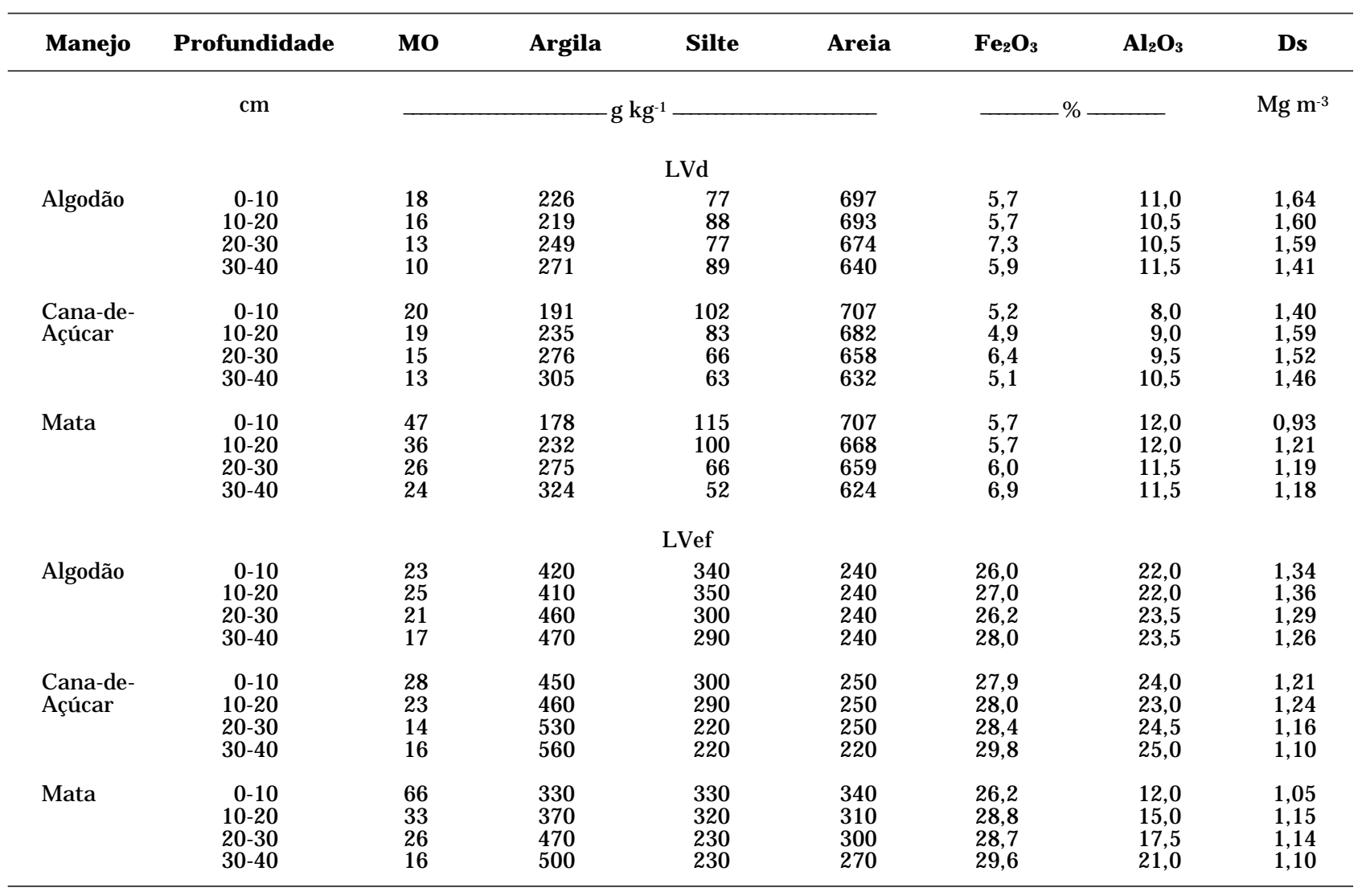

As amostras deformadas e indeformadas foram col etadas nas profundidades de 0-10; 10-20; 20-30 e $30-40 \mathrm{~cm}$. As amostras indeformadas, coletadas com auxílio de anéis volumétricos de $4,8 \mathrm{~cm}$ de diâmetro e 3,0 cm de altura, foram utilizadas para a determinação da densidade do solo, segundo o método da EMBRAPA (1997), da retenção de água, por secamento, nas tensões de 0,$001 ; 0,006 ; 0,01$; 0,033; 0,06; 0,1 e 0,3 MPa, em câmaras de pressão de Richards com placa porosa (EMBRAPA, 1997). As curvas de retenção de água foram ajustadas com base no modelo matemático proposto por Van Genuchten (1980), tendo sido estimada a retenção deágua a 1,5 MPa, com vistas em calcular a capacidade de água disponível (CAD), considerando a falta de equipamento para tal determinação.

Nas amostras deformadas, foram determinados os teores de carbono orgânico por oxidação, segundo EMBRAPA (1997), e o da matéria orgânica, multiplicando-se o teor de carbono orgânico pelo fator 1,724. A composição granulométrica foi obtida pela dispersão com água e $\mathrm{NaOH}\left(0,1 \mathrm{~mol} \mathrm{~L}^{-1}\right)$, agitação lenta (16 horas), e a argila foi determinada pelo método da pi peta, segundo método proposto pela EMBRAPA (1997). Nas amostras de solo coletadas na mata, realizou-sea oxidação da matéria orgânica antes de determinar a textura do solo. $\mathrm{O} \mathrm{Fe}_{2} \mathrm{O}_{3}$ e o $\mathrm{Al}_{2} \mathrm{O}_{3}$ foram determinados, segundo Camargo et al. (1986).

O delineamento experimental utilizado foi inteiramente casualizado, em esquema fatorial $2 \times 3$ (dois solos e três sistemas de manejo), com sete repetições. Os efeitos dos solos e dos sistemas de uso e manejo sobre os atributos físicos, nas diferentes profundidades estudadas, foram verificados a partir da análise de variância e, quando significativas, as médias foram comparadas pelo teste deTukey a $5 \%$.

\section{RESULTADOS E DISCUSSÃO}

Na figura 1, são apresentadas as curvas de retenção de água no Latossolo Vermel ho distrófico (LVd) e Latossol o Vermel ho eutroférrico (LVef), nos sistemas de uso e manejo e nas diferentes profundidades, ajustadas segundo o model o matemático proposto por Van Genuchten (1980). Observou-se quea retenção de água foi diferenciada nos solos, nos sistemas de uso e manejo e nas 

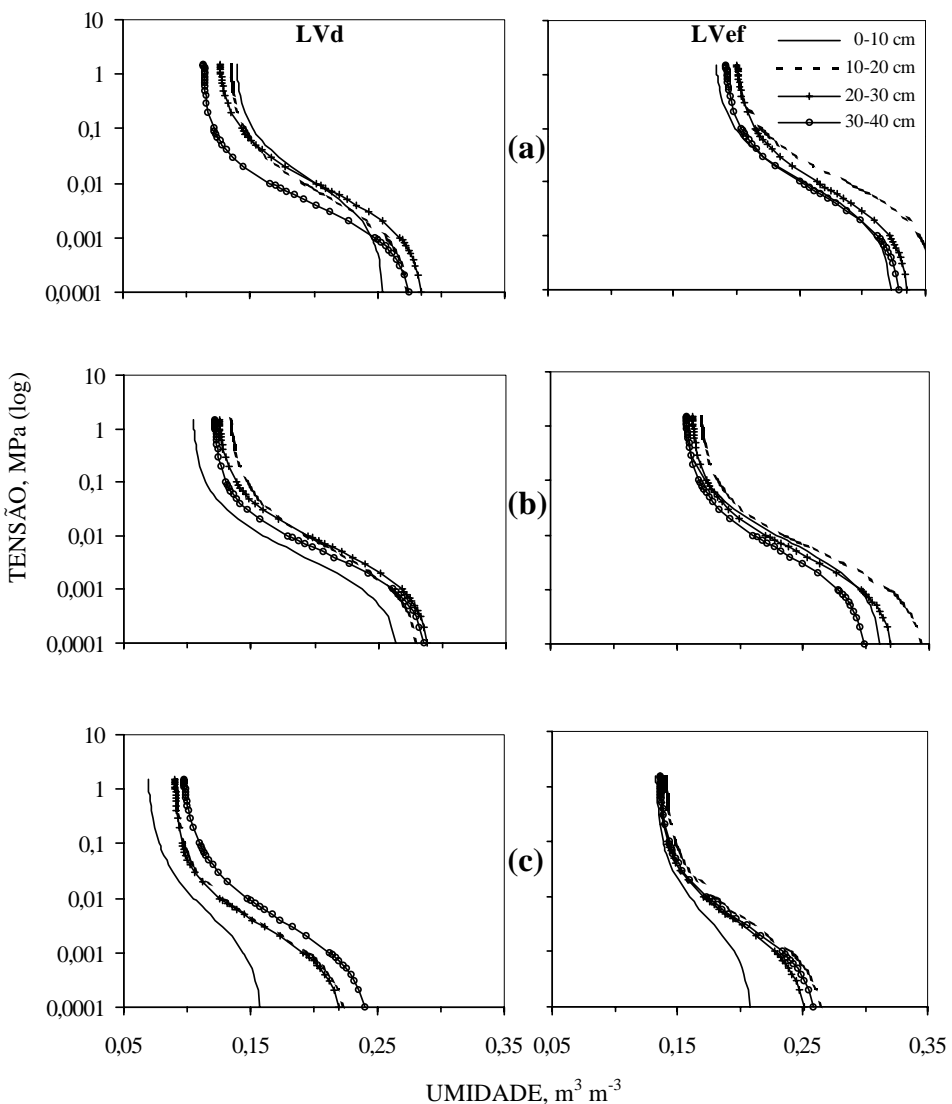

Figura 1. Curvas de retenção de água do Latossolo Vermelho distrófico caulinítico e Latossolo Vermelho eutroférrico oxídico, em quatro profundidades ((a) algodão; (b) cana-de-açúcar; (c) mata nativa).

profundidades, indicando que os atributos dos solos influenciaram o conteúdo de água retido nas diferentes tensões.

NoLVef, verificou-se maior retenção de água, em todas as tensões, bem como decréscimo mais gradual do conteúdo de água com o aumento da tensão em todos sistemas de uso e profundidades do solo, comparado ao LVd de textura mais grossa, corroborando com Reichardt (1987) e Demattê (1988). Esses autores afirmaram que, em solos de textura mais fina, a distribuição dos poros por tamanho é maior e mais uniforme, proporcionando a adsorção de maior conteúdo de água e decréscimo mais gradual da umidade do solo com o aumento da tensão.

No LVef, a maior retenção de água em baixas tensões deveu-se, ainda, à mineralogia oxídica da fração argila, que promove a formação de mi cropeds (mi croagregados) arredondados com menos de $1 \mathrm{~mm}$, onde predominam poros de empacotamento composto entreestes e destes com grãos não envol tos de plasma, formando um aspecto maciço poroso "in situ", promovendo maior proporção de poros grandes e menor densidade do solo (Ferreira et al., 1999). Em altas tensões, o maior teor de argila foi responsável por maior retenção de água, visto que, acima da tensão de 0,02 Mpa, a porosidade deixa de ser relevante na retenção de água (Demattê, 1988), comparado ao LVd, em que a caulinita predomina na fração argila.

A quantidade de matéria orgânica teve pouca influência na retenção de água no sol o cultivado com al godão e cana-de-açúcar, concordando com os estudos de Grohmann \& Medina (1962), em solos cultivados, em que pequenas variações no teor de matéria orgânica mostraram pouca influência na retenção de água, demonstrando que outros atributos, como a densidade do solo, tiveram maior importância.

Na mata, com teores de matéria orgânica acima de $47 \mathrm{~g} \mathrm{~kg}^{-1}$, na camada de 0-10 cm, ocorreu menor retenção deágua, em todas as tensões, nos dois solos, quando comparados aos das camadas inferiores com menores teores de matéria orgânica. Todavia, ocorreu incremento no conteúdo de argila e maior densidade do solo, com o aumento da profundidade, promovendo efeito positivo esuperior ao da matéria orgânica na retenção de água. Neste sentido, segundo Grohmann \& Medina (1962), em perfil heterogêneo em relação à textura, a importância da matéria orgânica na retenção de água pelo solo é menos evidente. 
Nos sistemas de cultivo de algodão e cana-deaçúcar, a maior retenção de água, nos dois solos e em todas as tensões, mostrou-se relacionada com a maior densidade do solo comparado à mata, corroborando os resultados de Corsini et al. (1986). Esses autores verificaram quea quantidade deágua aumentou, independentemente da tensão, considerando o tempo após o cultivo e a intensidade de preparo, ocorrendo o mesmo com a densidade do solo, em sistemas de cultivo de cana-de-açúcar.

Dentre as informações obtidas pelas curvas de retenção de água, destaca-se a capacidade de água disponível (CAD), importante para o crescimento radicular, para as reações químicas, movimento e absor ção de nutrientes e conseqüente produção das culturas. A CAD corresponde à diferença entre o conteúdo de água retido na capacidade de campo de $-0,006 \mathrm{MPa}$ (Reichardt,1988) e no ponto de murcha permanentede-1,5 MPa. No quadro 2, éapresentada a CAD nos solos e nos sistemas de uso e manejo.

Quadro 2. Capacidade de água disponível ${ }^{(1)}$, na profundidade de $0-40 \mathrm{~cm}$, nos sistemas de manejo, no LVd e no LVef

\begin{tabular}{lccc}
\hline \multirow{2}{*}{ Manejo } & \multicolumn{2}{c}{ Capacidade de água disponível $\left(\mathbf{m}^{\mathbf{3}} \mathbf{~ m}^{\mathbf{3}}\right)$} \\
\cline { 2 - 4 } & LVd & LVef & Média \\
\hline Algodão & 0,079 & 0,086 & $0,083 \mathrm{a}$ \\
Cana-de-açúcar & 0,079 & 0,080 & $0,080 \mathrm{a}$ \\
Mata & 0,052 & 0,046 & $0,049 \mathrm{~b}$ \\
Média & $0,070 \mathrm{~A}$ & $0,071 \mathrm{~A}$ & \\
C.V. (\%) & & 13,91 & \\
\hline
\end{tabular}

Médias seguidas pela mesma letra maiúscula, na linha, e minúscula, na coluna não diferem entre si $(P \leq 0,05)$.

(1) Capacidade de Água Disponível = retenção de água na CC (-0,006 MPa) - PMP (-1,5 MPa).
A CAD foi a mesma para os dois solos, apesar da mai or retenção deágua, em todas as tensões, noLVef, comparado ao LVd de textura mais grosseira. I sto demonstra que o maior conteúdo de água retido no LVef não resultou em benefício para as plantas, graças à retenção da água com maior tensão, permanecendo indisponível para as plantas. A mesma CAD para os dois solos demonstra a importância da estrutura, relacionada com o conteúdo e mineralogia da fração argila, na retenção de água, corroborando Demattê (1988).

A mata apresentou o maior teor de matéria orgânica e a menor densidade do solo, no entanto, apresentou a menor CAD. Estes resultados permitem inferir que a matéria orgânica mel hora a estrutura do solo, mas não a retenção de água, quando ocorrem variações na densidade do solo, ou seja, a densidade dosol osuperior nos sol os cultivados teve efeito positivo esuperior ao da matéria orgânica na CAD.

No quadro 3, são apresentadas as correlações de Pearson entre os atributos do solo e a retenção de água na capacidade de campo (CC) e no ponto de murcha permanente(PMP). A matéria orgânica não teve correlação com a retenção de água na CC ePMP, quando a correl ação foi real izada com todos os dados, concordando com os estudos de Centurion \& Andrioli (2000), que não verificaram participação efetiva da matéria orgânica na retenção de água. Neste sentido, Zimback (1993) verificou a eficiência significativa da matéria orgânica na retenção de água somente em horizontes arenosos. Estes resultados indicam que a matéria orgânica tem pouca influência na retenção de água em meios heterogêneos em relação à textura e densidade do solo, confirmando pesquisas de Grohmann \& Medina (1962).

Quadro 3. Correlações de Pearson entre a retenção de água na capacidade de campo (CC) e ponto de murcha permanente (PMP) e os teores matéria orgânica (MO), argila, $\mathrm{Fe}_{2} \mathrm{O}_{3}, \mathrm{Al}_{2} \mathrm{O}_{3}$ e a densidade do solo (Ds), no LVd e no L Vef

\begin{tabular}{|c|c|c|c|c|c|}
\hline & MO & Argila & $\mathrm{Fe}_{2} \mathrm{O}_{3}$ & $\mathrm{Al}_{2} \mathrm{O}_{3}$ & Ds \\
\hline & & & LVd & & \\
\hline \multirow[t]{2}{*}{ PMP } & $\begin{array}{c}-0,86^{* *} \\
-0,81^{* *}\end{array}$ & $\begin{array}{l}0,18^{\mathrm{NS}} \\
0,14^{\mathrm{NS}}\end{array}$ & $\begin{array}{r}0,04^{N S} \\
-0,09^{N S}\end{array}$ & $\begin{array}{l}-0,55^{\mathrm{NS}} \\
-0,48^{\mathrm{NS}}\end{array}$ & $\begin{array}{l}0,97^{* *} \\
0,98^{* *}\end{array}$ \\
\hline & & & LVef & & \\
\hline \multirow[t]{2}{*}{ PMP } & $\begin{array}{l}-0,43^{\mathrm{NS}} \\
-0,35^{\mathrm{NS}}\end{array}$ & $\begin{array}{l}0,15^{\mathrm{NS}} \\
0,10^{\mathrm{NS}}\end{array}$ & $\begin{array}{l}-0,41^{\mathrm{NS}} \\
-0,49^{\mathrm{NS}}\end{array}$ & $\begin{array}{l}0,70^{*} \\
0,60^{*}\end{array}$ & $\begin{array}{l}0,93^{* *} \\
0,91^{* *}\end{array}$ \\
\hline & & & Vde L Vef & & \\
\hline $\mathrm{CC}$ & $-0,36^{\mathrm{NS}}$ & $0,57^{*}$ & $0,57^{*}$ & $0,66^{*}$ & 0,30 NS \\
\hline PMP & $-0,19^{\mathrm{NS}}$ & $0,71^{* *}$ & $0,73^{* *}$ & $0,77 * *$ & 0,09 NS \\
\hline
\end{tabular}

**, * , NS Significativos a 1 e $5 \%$ e não-significativo, respectivamente. CC (-0,006 MPa) e PMP (-1,5 MPa). 
A análise conjunta dos dados (LVd e LVef) (Quadro 3) indicou que os teores de argila e dos óxidos deFeeAl apresentaram cor relações positivas esignificativas com a retenção deágua, confirmando o efeito desses colóides na retenção de água, conforme mencionado por Demattê (1988). A densidade do solo apresentou a maior correlação, positiva esignificativa, com a retenção de água, em cada solo.

\section{CONCLUSÕES}

1. O teor deargila ea densidade do solo opresentaram efeitos positivos e mais pronunciados na retenção de água, em todas as tensões, em relação à matéria orgânica. A densidade do sol o foi o atributo que teve maior influência na retenção de água, em cada solo.

2. Correlações positivas entrea retenção deágua e os óxidos de ferro e alumíni o foram observadas em todas as tensões.

3. O LatossoloVermel ho eutroférrico oxídico reteve maior conteúdo de água em todas as tensões, porém apresentou a mesma capacidade deágua disponível em relação ao Latossolo Vermelho distrófico caulinítico.

\section{LITE RATURA CITADA}

BRADY, N.C. Natureza e propriedades dos solos. 7.ed. Rio de J aneiro: Freitas Bastos, 1989. 898p.

CAMARGO, A.; MONIZ, A.C.; J ORJ E, J.A. \& VALADARES, J.M.A.S. Métodos de análise química, mineralógica e física de solos. Campinas: Instituto agronômico de Campinas, 1986. 94p. (Circular, 10)

CARVALHO, E.J.M.; FIGUEIREDO, M.S. \& COSTA, L.M. Comportamento físico-hídrico de um Podzólico VermelhoAmarelo câmbico fase terraço sob diferentes sistemas de manejo. Pesq. Agropec. Bras., 34:257-265, 1999.

CENTURION, J.F. \& ANDRIOLI, I. Regime hídrico de alguns solos de J aboticabal. R. Bras. Ci. Solo, 24:701-709, 2000.

CENTURION, J.F. \& DEMATTÊ, J.L.I. Efeitos de sistemas de preparo nas propriedades físicas de um solo sob cerrado cultivado com soja. R. Bras. Ci. Solo, 9:263-266, 1985.

CORSINI, P.C.; MALHEIROS, E.B. \& SACCHI, E. Sistemas de cultivo da cultura de cana-de-açúcar: efeitos na retenção de água e na porosidade do solo. R. Bras. Ci. Solo, 10:7174, 1986.

DEMATTÊ, J.L.I. Manejo de solos ácidos dos trópicos úmidosregião amazônica. Campinas: Fundação Cargill, 1988. $215 p$.
DIAS J UNIOR, M.S. \& ESTANISLAU, W.T. Grau de compactação e retenção de água de Latossolos submetidos a diferentes sistemas de manejo. R. Bras. Ci. Solo, 23:45-51, 1999.

ELTZ, F.L.F.; PEIXOTO, R.T.G. \& J ASTER, F. Efeitos de sistemas de preparo do solo nas propriedades físicas e químicas de um Latossolo Bruno álico. R. Bras. Ci. Solo, 13:259-267, 1989.

EMPRESA BRASILEIRA DE PESQUISA AGROPECUÁRIA EMBRAPA. Manual de métodos de análises do solo. 2 ed. Rio de Janeiro, Ministério da Agricultura e do Abastecimento, 1997. 212p.

FERREIRA, M.M.; FERNANDES, B. \& CURI, N. Mineralogia da fração argila e estrutura de $L$ atossol os da região sudeste do Brasil. R. Bras. Ci. Solo, 23:507-514, 1999.

GROHMANN, F. \& MEDINA, H.P. Características de umidade dos principais solos do estado de São Paulo. Bragantia, 21:285-295, 1962.

HILLEL, D. Solo e água, fenômenos e princípios físicos. Porto Alegre, Universidade Federal do Rio Grande do Sul, 1970. 231p.

KIEHL,E.J . Manual deedafologia. São Paulo, Agronômica Ceres, 1979. 262p.

PORTELA, J.C.; LIBARDI, P.L. \& van LIER, Q.J. Retenção de água em solo sob diferentes usos no ecossistema tabuleiros costeiros. R. Bras. Eng. Agríc. Ambiental, 5:49-54, 2001.

REICHARDT, K. A água em sistemas agrícolas. São Paulo, 1987. 188p.

REICHARDT, K. Capacidade de campo. R. Bras. Ci. Solo, 12:211-216, 1988.

SIDIRAS, N.; DERPCH, R. \& MONDARDO, A. Influência de diferentes sistemas de preparo do solo na variação da umidadee rendimento da soja, em Latossolo Roxo Distrófico (Oxisol). R. Bras. Ci. Solo, 7:103-106, 1983.

SIDIRAS, N.; VIEIRA, S.R. \& ROTH, C.H. Determinação de algumas características físicas de um Latossolo Roxo distrófico sob plantio direto e preparo convencional. R. Bras. Ci. Solo, 8:265-268, 1984.

SILVA, A.P.; LIBARDI, P.L. \& CAMARGO, O.A. Influência da compactação nas propriedades físicas de dois Latossolos. R. Bras. Ci. Solo, 10:91-95, 1986.

van GENUCHTEN, M.T.A. A dosed-form equation for predicting the hydraulic conductivity of unsaturated soils. Soil Sci. Soc. Am. J., 44:892-897, 1980.

VIEIRA, M.J. Propriedades físicas do solo. In: FUNDAÇÃO INSTITUTO AGRONÔMICO DO PARANÁ. Plantio direto no Estado do Paraná. Londrina, Instituto Agronômico do Paraná, 1981. p.19-30 (Circular, 23)

ZI MBACK, C.R.L. Levantamento semidetal hado ecaracterização hídrica de solos provenientes do grupo bauru, em duas bacias hidrográficas, na região de Marília-SP. Botucatu, Universidade Estadual Paulista, 1993. 184p. (Tese de Doutorado) 